\title{
Integrated analytic hierarchy process and its applications - a literature review
}

\author{
William Ho \\ Operations and Information Management Group \\ Aston Business School, Aston University \\ Birmingham B4 7ET, United Kingdom \\ E-mail: w.ho@aston.ac.uk; Tel: +44 (0)121 2043342
}

\begin{abstract}
Due to its wide applicability and ease of use, the analytic hierarchy process (AHP) has been studied extensively for the last 20 years. Recently, it is observed that the focus has been confined to the applications of the integrated AHPs rather than the stand-alone AHP. The five tools that commonly combined with the AHP include mathematical programming, quality function deployment (QFD), meta-heuristics, SWOT analysis, and data envelopment analysis (DEA). This paper reviews the literature of the applications of the integrated AHPs. Related articles appearing in the international journals from 1997 to 2006 are gathered and analyzed so that the following three questions can be answered: (i) which type of the integrated AHPs was paid most attention to? (ii) which area the integrated AHPs were prevalently applied to? (iii) is there any inadequacy of the approaches? Based on the inadequacy, if any, some improvements and possible future work are recommended. This research not only provides evidence that the integrated AHPs are better than the stand-alone AHP, but also aids the researchers and decision makers in applying the integrated AHPs effectively.
\end{abstract}

Keywords: Analytic hierarchy process; Mathematical programming; Quality function deployment; Meta-heuristics; SWOT analysis; Data envelopment analysis. 


\section{Introduction}

The AHP, developed by Saaty (1980), has been studied extensively and used in almost all the applications related with multiple criteria decision making (MCDM) in the last 20 years. Steuer and Na (2003) revealed that there were about 18 articles studying the AHP combined with finance simply, whereas Vaidya and Kumar (2006) found that there were 150 articles investigating the AHP combined with general applications. Besides applying to the finance sector (Steuer and Na, 2003), the AHP was adopted in education, engineering, government, industry, management, manufacturing, personal, political, social, and sports (Vaidya and Kumar, 2006). The wide applicability is due to its simplicity, ease of use, and great flexibility. It can be integrated with other techniques, for instance, mathematical programming in order to consider not only both qualitative and quantitative factors, but also some real-world resource limitations. This approach, regarded as the integrated AHP, can definitely make a more realistic and promising decision than the stand-alone AHP. More focus, therefore, has been confined to the integrated AHPs recently.

The present study is different from Steuer and Na (2003) and Vaidya and Kumar (2006), in which the applications of the stand-alone AHP were mainly reviewed. In this paper, the author is going to survey the applications of the integrated AHPs through a literature review and classification of the international journal articles from 1997 to 2006. The tools integrated with the AHP include mathematical programming, QFD, meta-heuristics, SWOT analysis, and DEA. These tools were selected because of their popularity, wide applicability, and success in making decisions. Based on the 66 journal articles collected (searched via Emerald, Ingenta, MetaPress, ProQuest, and ScienceDirect), three issues are examined, including: (i) which type of the integrated AHPs was paid most attention to? (ii) which area the integrated AHPs were prevalently applied to? (iii) is there any inadequacy of the approaches?

The next section explains the mechanism of the AHP briefly. The sections following this describe the tools integrated with the AHP and their applications critically. Analysis of the integrated AHPs, suggestions for future work, and conclusions of this paper are carried out in the last sections.

\section{Analytic hierarchy process}

The AHP consists of three main operations, including hierarchy construction, priority analysis, and consistency verification. First of all, the decision makers need to break down complex multiple criteria decision problems into its component parts of which every possible attributes are arranged into multiple hierarchical levels. After that, the decision makers have 
to compare each cluster in the same level in a pairwise fashion based on their own experience and knowledge. For instance, every two criteria in the second level are compared at each time with respect to the goal, whereas every two attributes of the same criteria in the third level are compared at a time with respect to the corresponding criterion. Since the comparisons are carried out through personal or subjective judgments, some degree of inconsistency may be occurred. To guarantee the judgments are consistent, the final operation called consistency verification, which is regarded as one of the most advantages of the AHP, is incorporated in order to measure the degree of consistency among the pairwise comparisons by computing the consistency ratio. If it is found that the consistency ratio exceeds the limit, the decision makers should review and revise the pairwise comparisons. Once all pairwise comparisons are carried out at every level, and are proved to be consistent, the judgments can then be synthesized to find out the priority ranking of each criterion and its attributes. The overall procedure of the AHP is shown in Fig. 1.

\section{Mathematical programming and its applications}

Among 66 journal articles, 33 papers (50\%) integrated the AHP with the mathematical programming techniques, including linear programming (LP), integer linear programming (ILP), mixed integer linear programming (MILP), and goal programming (GP). The combined AHP-mathematical programming approaches and their applications are summarized in Table 1.

\subsection{Combined AHP-LP approach}

Ghodsypour and O’Brien (1998) adopted the AHP to determine the relative importance weightings of the suppliers with respect to three criteria: cost, quality, and service. The weightings were then incorporated into the objective function of a LP model. The model is to select the optimal set of suppliers in terms of weightings, and determine the amount of raw materials to be purchased from the suppliers so that the customer demand is met, and the supplier's capacity constraint is not violated.

Saaty et al. (2003) studied the resource allocation problem in two merging companies. Tangible and intangible resources were allocated to proper management areas so that positive synergistic effects could be created. The AHP was used first to obtain the relative importance weightings of alternative management areas, such as markets, innovation, and cost reduction. The AHP weightings were then utilized as the weighting factors in the objective function of the LP model, with the objective of maximizing the benefits of the merged company. 
Lee and Hsu (2004) constructed a LP model first to estimate the net IC product demand. The product demand was then transformed into capacity demands. Following that, the AHP was used to evaluate the relative performance of the subcontractors with respect to three criteria: management, technology, and cost. Based on the above data, capacity was allocated to the subcontractors with higher AHP weightings in advance. The allocation would be completed if all capacity demands are met.

\subsection{Combined AHP-ILP approach}

Malczewski et al. (1997) used the combined AHP-ILP approach to aid the land use planning. The AHP was applied first to obtain the relative importance weightings of alternative interest groups. The AHP weightings were then utilized as weighting factors in the objective function of the ILP model, which aims at maximizing the consensus among the interest groups.

Braglia et al. (2001) used the AHP to determine the relative importance weightings of alternative material handling devices. The evaluation criteria are cost, benefit, and compatibility of each device with respect to each manufacturing cell. The weightings were then incorporated into an ILP model, of which the objective is to select a set of devices with the maximum weighting. Several resource constraints were considered, such as budget and space.

Akgunduz et al. (2002) developed an ILP model to select the best combination of alternatives for sub-components and parts, with the objectives of maximizing the customer satisfaction and minimizing the product cost. The values of the objective functions coefficients were determined by using an AHP-like pairwise comparison technique. The higher the value, the more important the objective is. Before selection, the AHP was adopted to evaluate the alternatives and assign weightings to them.

Çebi and Bayraktar (2003) proposed the AHP to evaluate the relative performance of the suppliers for every raw material. The evaluation criteria include lead time, problem solving skill, reputation, and so on, which are very similar to those proposed by Ghodsypour and O’Brien (1998). The weightings of the suppliers were then used as the input of an ILP model in order to select the best set of suppliers for a particular type of raw materials, and determine the amount of raw materials to be purchased from the suppliers.

Kearns (2004) proposed the AHP to evaluate the relative importance weightings of alternative information systems. The evaluation was on the basis of five criteria: investment risk, revenue enhancing, operating efficiency, customer satisfaction, and market growth. 
Similar to Ghodsypour and O'Brien (1998), the AHP weightings were used as the priority coefficients in the objective function of the ILP model. The objective of the model is to select the best combination of information systems, while not exceeding the budget constraint.

Ozdemir and Gasimov (2004) formulated a binary nonlinear programming model with multiple objectives for the faculty course assignment problem. Due to the complexity of the model, they reduced the multiple objective functions to a single objective function. The AHP was used to determine the relative importance weightings of the objectives or the preferences of instructors and administrators. The reduced ILP model was to select the best assignment so that the instructor and administrator satisfaction was maximized.

\subsection{Combined AHP-MILP approach}

Tyagi and Das (1997) studied an integrated logistics distribution problem in which not only the manufacturers and warehouses were selected to serve the warehouses and customers, respectively, but also the shipment quantities were determined. To solve the problem, a two-stage approach was developed. In the first stage, a MILP model was formulated. Rather than solving the model to optimality, alternative heuristic solutions were generated. In the second stage, the AHP was used to evaluate and select the best solution with respect to three criteria: total cost, delivery time, and service rating.

Korpela and Lehmusvaara (1999) studied a general logistics distribution problem. It is to determine: (i) which third-party warehouse operators are selected to serve the customers; (ii) how many products are distributed to the customers. In their approach, the AHP was used first to measure the relative importance weightings of alternative operators based on three criteria: reliability, flexibility, and customer's logistics costs. The AHP weightings were then used as weighting factors in the objective function of the MILP model, with the objective of maximizing customers' satisfaction.

Korpela et al. (2001a) extended the problem studied in Korpela and Lehmusvaara (1999). Not only the third-party warehouse operators, the sea transportation service providers and haulers were also evaluated using the AHP. The evaluation criteria include reliability of delivery time, reliability of condition of products, flexibility of urgent deliveries, flexibility of capacity, cost level, and value added services. Similarly, the AHP weightings were incorporated into the objective function of the MILP model, with the objective of maximizing the customers' satisfaction.

Korpela et al. (2001b) studied the same logistics distribution problem and used the same approach as in Korpela and Lehmusvaara (1999). The only difference is that two new 
factors were considered. They are strategic importance of customers and environmental performance of transportation routes. The AHP was used to evaluate the relative importance weightings of these factors.

Korpela et al. (2002) used the combined AHP-MILP approach to deal with the general logistics distribution problem again. Among the three factors, the strategic importance of the customers and performance of alternative routes were already adopted in Korpela and Lehmusvaara (1999), Korpela et al. (2001a; 2001b). Only the third factor (i.e., the risk related to supplier-customer relationship) in Korpela et al. (2002) differentiated their approach with the previous three publications.

Crary et al. (2002) applied the AHP to evaluate the relative importance weightings of alternative ships with respect to various missions in the US Navy. A MILP incorporating with the AHP weightings was formulated to select the best combination of ships for a particular mission, and determine the optimal number of ships for the missions. The objective of the MILP model is to maximize the fleet effectiveness or the probability of winning the wars.

Malladi and Min (2005) applied the combined AHP-MILP approach to select the best high-speed Internet access technology for each rural community. Based on cost, quality, and speed, the technologies were compared with each other to generate the AHP priority weightings. They were then utilized as the weighting factors in the objective function of the MILP model. Budget was the only resource limitation considered in the model.

Stannard and Zahir (2006) used the combined AHP-MILP approach to determine the optimal allocation of a limited number of aircraft among a group of airlift users with varying levels of priority and length of usage. The AHP was used to evaluate the relative importance weightings of alternative tasks of airlift users in advance. The evaluation criteria include system training value, user category, and effective use of the aircraft. The AHP weightings were then incorporated into the objective function of the MILP model, with the objective of maximizing the total worth of the airlift use.

\subsection{Combined AHP-GP approach}

Schniederjans and Garvin (1997) applied the combined AHP-GP approach to evaluate and select the best combination of cost drivers. First, the AHP was used to determine the relative importance weightings of alternative cost drivers with respect to four criteria: correlation with cost, reduction of drivers, performance, and cost of measure. The AHP weightings were then utilized as one of the goal constraints besides budgeted cost, analyst hours, and auditing hours. 
Kwak and Lee (1998) studied the problem of allocating higher education institution's resources to IT-based projects. In their approach, the AHP was used first to evaluate the relative importance weightings of alternative networking methods (one of the IT-based projects) with respect to four criteria: risk, performance, conversion, and development. The weightings were then incorporated into the objective function of the GP model. The model was to select the optimal combination of projects to be invested. Budget was the only resource limitation considered in the model.

Radasch and Kwak (1998) applied the combined AHP-GP approach to aid the offset planning. The AHP was used first to evaluate the relative importance weightings of alternative offset proposals with respect to four criteria: economic, social, political, and company. The AHP weightings were then incorporated into the GP model.

Badri (1999) used the combined AHP-GP approach to deal with the location-allocation problem. First, the AHP was adopted to evaluate the alternative locations with respect to several criteria, such as political situation, global competition and survival, government regulations, and economics related factors. After assigning importance weightings to the alternative locations, a GP model was formulated to select the best combination of alternatives based on the resource limitations (e.g., budget and country restriction for air quality), and determine the allocation of products from locations to distribution centers.

Guo and He (1999) applied the AHP to evaluate the relative importance weightings of various harvesting measures for improving the grain harvesting and post-harvesting system in China. A GP model was developed to select the best combination of alternative measures according to the AHP weightings. Some resource limitations were considered in the model, such as budgeting, manpower, facility/equipment, and so on.

Kim et al. (1999) adopted the AHP to evaluate the relative importance weightings of several nuclear fuel cycle scenarios with respect to five intangible factors, such as energy security, economics, technological feasibility, domestic issues, and international relations. As the case with Ghodsypour and O'Brien (1998), the AHP weightings were utilized in the objective function as weighting factors. Besides incorporating the intangible factors into the GP model, some tangible factors, including fuel requirement, total discounted cost, cost sensitiveness, and environmental impact were considered.

Lee and Kwak (1999) applied the combined AHP-GP approach to deal with the resource allocation problem in the health-care system. The relative importance weightings of alternative networking methods obtained by the AHP were incorporated into the objective function of the GP model. Budget and human resources were considered in the model. 
Zhou et al. (2000) applied the combined AHP-GP approach to tackle the scheduling problem in a petrochemical company. First, the AHP was adopted to determine the priority ranking of the four goals: economic sustainability, social sustainability, resource sustainability, and environment sustainability. Based on the AHP ranking, the GP model was formulated in which several resource limitations were considered, such as capacity of warehouses and vehicles, budget, and so on.

Similar to Badri (1999), Badri (2001) applied the combined AHP-GP approach to design quality control systems in the service-based organizations. First, the AHP was used to obtain the relative importance weightings of alternative customer data collection methods with respect to several service quality criteria, including responsiveness, assurance, reliability, empathy, and tangibles. Then, a GP model was constructed to select the best combination of alternatives based on the resource limitations (e.g., budget and human resources).

Although Kwak and Lee (2002) used the combined AHP-GP approach as the case with Kwak and Lee (1998), they focused on the resource allocation problem in the health-care system instead of higher education institution. Besides, rather than incorporating the AHP weightings into the objective function, the authors used the AHP to determine the priority ranking of the goals in the GP model. The evaluation criteria include effectiveness, care delivery, partnership, competitiveness, and cost. The objective of the approach is to select the best set of projects so that the performance of the health-care system can be enhanced, while the resource constraints (e.g., budget and human resources) are not violated.

Radcliffe and Schniederjans (2003) believed that building trust in a scientific virtual project team is important. They used the combined AHP-GP approach to evaluate and select the best combination of alternative trust categories. The AHP was applied to obtain the relative importance weightings of the trust factors based on three criteria: management, technical, and support. The AHP weightings were incorporated into the GP model.

Similar to Ghodsypour and O’Brien (1998) and Çebi and Bayraktar (2003), Wang et al. (2004; 2005) focused on the supplier selection problem. There are two major differences between them. First, Ghodsypour and O’Brien (1998) and Çebi and Bayraktar (2003) applied the combined AHP-LP approach and the combined AHP-ILP approach, respectively, whereas Wang et al. (2004; 2005) adopted the combined AHP-GP approach. The second difference is due to the evaluation criteria used in the AHP. Wang et al. (2004; 2005) evaluated the relative importance weightings of alternative suppliers based on the delivery reliability, flexibility and responsiveness, cost, and asset. The AHP weightings were then incorporated into one of the goal constraints of the GP model. 
Yurdakul (2004) applied the combined AHP-GP approach to evaluate and select the optimal combination of computer-integrated manufacturing technologies. The AHP was used first to obtain the relative importance weightings of alternative technologies with respect to four criteria: innovation, customization, product proliferation, and price reduction. The AHP weightings were then incorporated into the GP model. Initial cost was the only resource limitation considered in the model.

Kwak et al. (2005) used the combined AHP-GP approach to evaluate and select the best combination of advertising media for a Korean company producing digital appliances. As the case with Kwak and Lee (2002), the authors adopted the AHP to obtain the overall relative importance of the goals in the GP model. The goals were compared based on each of three criteria, such as customer relations, advertising effects, and resource allocation.

Bertolini and Bevilacqua (2006) used the combined AHP-GP approach to find out the optimal maintenance policy for every critical centrifugal pump in an Italian oil refinery. The AHP was used first to evaluate the maintenance alternatives with respect to three criteria: occurrence, severity, and detectability. After that, a GP model was developed to select the best policy for each pump based on the resource limitations (e.g., budget and human resources).

\section{QFD and its applications}

Among 66 journal articles, 16 papers (24.2\%) applied the combined AHP-QFD approach to various situations. The papers are critically analyzed in the following, and their applications are summarized in Table 2.

Köksal and Eğitman (1998) applied the combined AHP-QFD approach to improve the education quality for the Department of Industrial Engineering at the Middle East Technical University. The AHP was adopted to evaluate the relative importance weightings of the stakeholder requirements. The alternative education design requirements were then prioritized based on the AHP weightings together with the relationship between the education requirements and stakeholder requirements. Those education requirements with higher scores should be targeted at.

Lam and Zhao (1998) used the combined AHP-QFD approach to identify appropriate teaching techniques. The AHP was used to evaluate the relative importance weightings of the students' requirements with respect to three criteria: skills development, interest and knowledge, and examination and job. Similar to Köksal and Eğitman (1998), the alternative teaching techniques were prioritized based on the AHP weightings and the relationship between students' requirements and teaching techniques. 
Wang et al. (1998) suggested that the whole house of quality can be represented as a hierarchy system if the AHP was used together with the QFD. The customer requirements and technical/design requirements in the QFD can therefore be regarded as the criteria and alternatives in the AHP, respectively. The relative importance weightings of the criteria and alternatives were obtained using the general AHP pairwise comparisons.

Partovi (1999) applied the combined AHP-QFD approach to aid the project selection. Unlike the approaches adopted by Köksal and Eğitman (1998), Lam and Zhao (1998), and Wang et al. (1998), the author used the AHP to quantify the strength of the relationships between rows (e.g., customer requirements) and columns (e.g., design specifications), instead of evaluate the relative importance weightings of decision alternatives.

Partovi and Epperly (1999) used the combined AHP-QFD approach to determine the composition of the United States peacekeeping force deployed in Bosnia. The objective was to guarantee that sufficient personnel and weapons systems were sent to achieve success. The AHP was used not only to evaluate the relative importance weightings of various stakeholders (e.g., American public, Bosnian Muslim, and so on), but also determine the intensity of the relationship between the variables involved in the three QFD matrices as the case with Partovi (1999). The matrices include: (i) linking stakeholders and their interest; (ii) linking stakeholder interests and peacekeeping activities; (iii) linking peacekeeping activities and force deployment.

Zakarian and Kusiak (1999) evaluated and selected the multi-functional teams using the combined AHP-QFD approach. Two QFD matrices were constructed. The first matrix relates the customer requirements to engineering characteristics, in which the customer requirements were prioritized using the AHP pairwise comparisons. The second matrix relates the engineering characteristics to team members, in which the relative importance weightings of engineering characteristics were obtained using the AHP again. Based on the second matrix, a team member with more impact on a particular engineering characteristic was selected.

Chuang (2001) applied the combined AHP-QFD approach to deal with the facility location problem. In the approach, a QFD matrix relating the location requirements (e.g., fast distribution ability, quick response to requirements, and so on) to location evaluating criteria (e.g., initial and operating costs, transportation conditions, and so on) was constructed. Based on the relative importance weightings of the location requirements obtained by using the AHP as well as the relationship between the requirements and evaluating criteria, the normalized importance degree of the evaluating criteria could be computed. The AHP was applied again to determine the relative importance weightings of alternative locations with respect to each 
evaluating criterion. A location with the total highest score was selected.

Hsiao (2002) used the combined AHP-QFD approach to aid the new product development. A QFD matrix relating the customer requirements to engineering requirements was constructed, in which the customer requirements were divided into two levels: criteria and sub-factors. The AHP was used to obtain the relative importance weightings of the criteria (i.e., assemblability, security, and aesthetics), but not the weightings of the sub-factors (e.g., high assembly efficiency, no toxicity, good appearance, and so on). The weightings of sub-factors, therefore, did not reflect the importance of the corresponding criteria.

Similar to Wang et al. (1998) and Hsiao (2002), Kwong and Bai (2002; 2003) applied the combined AHP-QFD approach to aid the new product development. However, it was argued that the pairwise comparison in the general AHP seems to be insufficient and imprecise to obtain the relative importance weightings of the customer requirements. Fuzzy number was therefore introduced in the pairwise comparison of the AHP.

Madu et al. (2002) applied the combined AHP-QFD approach to evaluate and select the functional characteristics of the environmentally friendly products. A QFD matrix linking the customer requirements (e.g., performance and cost effectiveness) and functional characteristics (e.g., number of times paper is recycled and cost of recycling) was constructed, in which the AHP was used to obtain the relative importance weightings of the customer requirements. Those functional characteristics with higher scores should be focused on.

Partovi and Corredoira (2002) used the combined AHP-QFD approach to prioritize and design rule changes for the game of soccer. The objective was to increase the attractiveness to soccer enthusiasts. In the approach, the AHP was used to determine the intensity of the relationship between the variables involved in the three QFD matrices. The matrices include: (i) linking market segments and customer's interests; (ii) linking customer's interests and soccer game activities; (iii) linking soccer game activities and laws of the game.

Myint (2003) proposed the combined AHP-QFD approach to aid the product design. Similar to Partovi (1999), Partovi and Epperly (1999), Zakarian and Kusiak (1999), and Partovi and Corredoira (2002), more than one QFD matrix was constructed. In the approach, four matrices were analyzed: (i) linking the customer requirements and assembly part characteristics (e.g., speed and weight); (ii) linking the assembly part characteristics and main assembly components (e.g., monitor and keyboard); (iii) linking the main assembly components and assembly sub-components (e.g., hard drive and CD-ROM); (iv) linking the assembly sub-components and assembly attributes (e.g., size and angle). The AHP was used to identify the priorities of customer requirements. 
Bhattacharya et al. (2005) applied the combined AHP-QFD approach to aid the robot selection. In the QFD, both customer requirements (e.g., payload and life-expectance) and technical requirements (e.g., drive system and weight of robot) were identified first. In order to obtain the importance weightings of the technical requirements, two inputs were needed: (i) the relationship between the customer and technical requirements; (ii) the relative importance weightings of customer requirements obtained by the AHP. After that, the AHP was adopted again to evaluate the relative importance weighting of each robot based on the technical requirements. The robot with the highest score was selected.

Partovi (2006) used the combined AHP-QFD approach to evaluate and select facility location for a company producing digital mass measurement weighted products for industrial use. The approach was akin to Partovi (1999), Partovi and Epperly (1999), and Partovi and Corredoira (2002), in which the AHP was used to determine the strength of the relationship between the variables involved in the four QFD matrices. The matrices include: (i) linking market segments and competitive priorities; (ii) linking competitive priorities and critical processes; (iii) linking critical processes and location attributes; (iv) linking location attributes and location alternatives.

Hanumaiah et al. (2006) presented the combined AHP-QFD approach to deal with the rapid tooling process selection. The AHP was adopted to determine the relative importance weightings of the tooling or customer requirements while considering constraints, such as material, geometric features, die material, and production quantity. Based on the AHP weightings, a QFD matrix relating the tooling requirements to alternative tooling processes was built in order to select an appropriate process.

\section{Meta-heuristics and their applications}

There are $12.1 \%$ of the papers (8 out of 66) incorporating the AHP into the meta-heuristics, including genetic algorithms or GA (7 papers) and artificial neural networks or ANN (1 paper). Table 3 lists the applications of the integrated AHPs.

Chang and Lo (2001) applied the combined AHP-GA/TS approach to deal with the job shop scheduling problem. The problem is to determine the sequence in which the operations of a set of jobs are to be performed by a finite number of machines. Rather than optimizing the problem by the general GA, two searching mechanisms of the TS (i.e., neighborhood search and tabu list) were incorporated into the GA in order to improve its performance. In the approach, the AHP was adopted first to: (i) determine the job sequence with respect to the qualitative criteria: market consideration, customer's relationship and historical business, and 
job profit/risk; (ii) evaluate the relative importance weightings of the quantitative criteria: due-date satisfaction, makespan, and machine utilization. Based on all these criteria, the GA/TS approach was then used to generate the best solution.

Kuo et al. (2002) presented the combined AHP-ANN approach to aid the location selection for a convenience store. The AHP was used first to assign the relative importance weightings to several evaluation factors: competition, magnet (e.g., crowd point), convenience, availability (e.g., stations), store characteristics, and population characteristics. The ANN was then applied to determine the relationship between these factors and the store performance in terms of the number of visiting customers per day.

As with the case of Tyagi and Das (1997), Chan and Chung (2004a) and Chan et al. (2004) studied the integrated logistics distribution problem. Similar to Tyagi and Das (1997), the authors did not solve the mathematical programming to optimality. Instead, the authors proposed the combined AHP-GA approach to obtain the near-optimal solutions. The GA was adopted first to explore and exploit alternative solutions heuristically. The AHP was then applied to evaluate the fitness of the alternative solutions with respect to four criteria: total cost, total delivery day, effectiveness of capacity utilization for manufacturing plants, and effectiveness of capacity utilization for warehouses. The solution with the total highest score was selected.

Chan and Chung (2004b) and Chan et al. (2005) studied the simplified version of problem mentioned in Chan and Chung (2004a). The manufacturers and customers were the only stakeholders considered in the supply chain. The solution approach adopted is akin to that of Chan and Chung (2004a), except that three instead of four evaluation criteria were used. The criteria include total cost, total delivery day, and effectiveness of capacity utilization for manufacturing plants.

Chan and Chung (2005) studied the integrated logistics distribution problem with the demand due date factor. Similar to Chan and Chung (2004a; 2004b) and Chan et al. (2004; 2005), the combined AHP-GA approach was applied to evaluate and select the best solution. The only difference is due to the evaluation criteria. Besides total cost, two new criteria were used to measure the fitness of the solutions: total lead time and tardiness.

Chan et al. (2006) studied the same problem and applied the same approach as Chan and Chung (2005). The only difference is due to the evaluation criteria used in the combined AHP-GA approach. Besides total cost, total lead time, and tardiness, effectiveness of capacity utilization was also considered. This criterion was already proposed in their previous papers, including Chan and Chung (2004a; 2004b) and Chan et al. (2004; 2005). 


\section{SWOT and its applications}

There are $7.6 \%$ of the papers (5 out of 66 ) incorporating the AHP into the SWOT analysis. The papers are analyzed critically in the following, whereas their applications are summarized in Table 4.

Kurttila et al. (2000) proposed the combined AHP-SWOT approach to aid the decision making in a Finnish forestry. There were two options faced by the forestry: (i) make a commitment to move to certified forestry; (ii) stay in timber-production-oriented forestry. First, the key factors concerning this strategic option were collected and classified using the SWOT analysis. The AHP was then used to measure the relative importance weightings of the SWOT group (i.e., strengths, weaknesses, opportunities, and threats), and the weightings of the SWOT factors with respect to the four criteria in the SWOT group. Based on the weightings, the overall priority of the factors was obtained.

Kajanus et al. (2004) proposed the combined AHP-SWOT approach to answer the question of whether culture can be a success factor in rural tourism. The approach was exactly the same as that presented previously in Kurttila et al. (2000).

Shrestha et al. (2004) analyzed the possibilities for silvopasture adoption in south-central Florida using the combined AHP-SWOT approach. The authors explained that the silvopasture is an agroforestry technology that combines trees and pasture with cattle operations. The approach was similar to those adopted by Kurttila et al. (2000) and Kajanus et al. (2004), in which the AHP was used to measure the relative importance weightings of the individual SWOT factors. Unlike the previous two approaches, the AHP weightings were obtained with respect to the key stakeholders, including research specialist, large landholder, and small landholder.

Besides applying to the agricultural planning as in Shrestha et al. (2004), Masozera et al. (2006) adopted the same approach to assess the suitability of community-based management method to the Nyungwe Forest Reserve in Rwanda. The AHP was used to determine the relative importance weightings of the SWOT factors with respect to the key stakeholders.

Shinno et al. (2006) presented the combined AHP-SWOT approach to analyze the global competitiveness of Japan's machine tool industry. To investigate the internal and external environments effectively of the industry, the SWOT analysis was adopted in which each of the four SWOT groups was further divided into three main sub-groups: market-related, organization-related, and product-related. As the case with previous approaches, the AHP was used to evaluate the relative importance weightings of the key factors in each sub-group. 


\section{DEA and its applications}

Comparatively, the combined AHP-DEA approach has attracted less attention. Only four journal articles (6.1\%) studied the applications of this approach, as shown in Table 5. The following paragraphs describe the characteristics and differences of the approaches.

Takamura and Tone (2003) presented the combined AHP-DEA approach to deal with the relocation of several government agencies out of Tokyo. First, the AHP was used to obtain the relative importance weightings of criteria (e.g., influence on the future of the country) and attributes (e.g., speedy response in a large-scale disaster). Second, based on the AHP weightings, the DEA was adopted to measure the effectiveness of alternative locations.

Yang and Kuo (2003) proposed the combined AHP-DEA approach to solve the facility layout design problem. A computer-aided layout planning tool called Spiral was adopted to generate a number of alternative layouts in advance. The relative importance weightings of alternative layouts were obtained by using the AHP pairwise comparison with respect to three qualitative factors: flexibility, accessibility, and maintenance. Following that, the DEA was used to solve the layout design problem by simultaneously considering both the qualitative and quantitative performance data (i.e., flow distance, adjacency, and shape ratio) leading to the identification of performance frontiers.

Saen et al. (2005) proposed the combined AHP-DEA approach to measure the relative efficiency of slightly non-homogeneous decision making units (DMUs). Due to the fact that some DMUs may lack of one or more feature (i.e., input and/or output), the AHP was used to estimate the missing value for a DMU close to reality as much as possible. For this, two alternatives were compared with respect to the attribute of the higher levels. The alternatives include: (i) the DMU which lacks the feature(s); (ii) the series means of other DMUs. The data for mean of other DMUs was obtained by taking the mean of each feature of all DMUs except the one which has missing value. The data was assumed to be normally distributed.

Ertay et al. (2006) applied the combined AHP-DEA approach to aid the facility layout design. The approach was very similar to that presented in Yang and Kuo (2003). First, a computer-aided layout planning tool called VisFactory instead of Spiral was adopted to generate a number of alternative layout designs. Second, the AHP was used to obtain the relative importance weightings of alternative layout designs with respect to two qualitative factors: flexibility and quality. Third, the DEA was used to evaluate the designs by simultaneously considering both qualitative and quantitative data, and select the best design. Besides the flow distance, adjacency, and shape ratio, which were proposed by Yang and Kuo (2003), material handling vehicle utilization and material handling cost were considered. 


\section{Observations and recommendations}

In this paper, 66 journal articles, which appeared in the period from 1997 to 2006, studying the integrated AHPs were collected. The tools integrated with the AHP include mathematical programming, QFD, meta-heuristics, SWOT, and DEA. These five integrated approaches and their applications have been summarized in Tables 1 to 5. Some observations based on these journal articles are made in the following sub-sections.

\subsection{The most popular integrated AHP}

The first objective of this paper is to find out the most popular integrated AHP(s), and this forms the first question. According to Tables 1 to 5, the most popular tool integrated with the AHP is mathematical programming (33 papers or 50\%), followed by QFD (16 papers or 24.2\%), meta-heuristics (8 papers or 12.1\%), SWOT (5 papers or 7.6\%), and DEA (4 papers or $6.1 \%)$. It was noted in Section 3 that there are four types of mathematical programming used together with the AHP, including LP, ILP, MILP, and GP. The combined AHP-GP has attracted the most attention (16 papers) during the last decade when compared with the combined AHP-LP (3 papers), AHP-ILP (6 papers), and AHP-MILP (8 papers) approaches. So, the combined AHP-GP and AHP-QFD approaches are the two most popular approaches.

The major reason why the combined AHP-GP approach was paid the most attention to is that the individual techniques possess unique advantages. Badri and Abdulla (2004) pointed out that "good decisions are most often based on consistent judgments". To prevent inconsistency, the consistency verification operation of the AHP contributes greatly because it acts as a feedback mechanism for the decision makers to review and revise their judgments. Consequently, the judgments made are guaranteed to be consistent, which is the basic ingredient for making good decisions. Nevertheless, the output of the AHP is the relative importance weightings of the criteria and the attributes merely. In some multiple criteria decision problems like facility location selection in logistics (Badri, 1999), besides the weightings of alternative locations, the decision makers also need to consider the resource limitations (e.g., budget and country restriction for air quality). For this reason, the GP can compensate for the AHP. It can definitely provide more and useful information for the decision makers. Based on the above analysis, it is believed that it must be beneficial to the decision making process if both AHP and GP are integrated together.

The most important information that the QFD provides is the importance weightings of design (product or service) attributes, which are derived by the importance ratings of customer requirements together with the relationship between customer requirements and 
design attributes. Generally, the importance ratings of customer requirements are determined by the decision makers arbitrarily. This may result in a certain degree of inconsistency, and therefore degrade the quality of decisions made. To overcome this drawback, the AHP is used to evaluate the relative importance weightings of customer requirements. This is the critical reason why the combined AHP-QFD approach was prevalently adopted.

\subsection{The most popular application area}

The second objective of this paper is to discover the most popular application area of the integrated AHPs. According to Table 6, it is observed that the applicability of the integrated AHPs is wide. They can be applied to 14 different fields in which, actually, there are different kinds of problems. Among these 14 fields, logistics has attracted the most attention, followed by manufacturing, government, higher education, business, environment, military, agriculture, health-care, marketing, industry, service, sports, and tourism. In summary, logistics (21 papers or 31.8\%) is the most popular application area.

As shown in Table 7, the problems studied in the logistics field include the transportation route selection (11 papers), supplier/subcontractor selection (5 papers), facility/convenience store location selection (4 papers), and scheduling plan selection (1 paper). It is observed that there are only two approaches used to evaluate and select the optimal transportation route. They are the combined AHP-GA and AHP-MILP approaches. Since both GA and MILP are optimization techniques, they can be applied desirably to this kind of problems. Except the combined AHP-SWOT and AHP-DEA approaches, it is found that all the other integrated AHPs have been applied to the logistics fields. Nevertheless, these two approaches can certainly be appropriate in this field. For example, the combined AHP-DEA approach can be used to evaluate the performance of suppliers or other stakeholders in a supply chain.

Manufacturing is the second most popular application area (18 papers or 27.3\%). The total percentage of papers focusing on both logistics and manufacturing is 59.1\%. According to Table 8 , there is a wide variety of problems studied in the manufacturing field, such as product design selection, facility layout selection, material handling device selection, sub-component selection, computer-integrated manufacturing technology selection, maintenance strategy selection, capital budgeting project selection, multi-functional team selection, robot selection, rapid tooling process selection, job shop schedule selection, and factor evaluation in competitive analysis. Product design selection (6 papers) is the most commonly studied problem. Not surprisingly, all these six papers proposed the combined 
AHP-QFD approach to evaluate and select the best alternative design specifications for the products. The major reason is that QFD is a promising technique for the design and development of new products or services with respect to the customer desires. Unlike the logistics field, all the five integrated AHPs were adopted to aid the evaluation and selection in the manufacturing field.

\subsection{Recommendations}

The last objective of this paper is to critically analyze the approaches, and try to find out some drawbacks. Some recommendations are then made based on the inadequacies. Instead of analyzing every single approach, the main focus of this section is confined to those applied to the transportation route selection and product design selection. The reason is that these two problems have attracted the most attention, as discussed in Section 8.2.

For the transportation route selection, both combined AHP-GA and AHP-MILP approaches were applied. The major difference between them is due to the application of the AHP. In the combined AHP-GA approach (Chan and Chung, 2004a; 2004b; 2005; Chan et al., 2004; 2005; 2006), the AHP was used as the fitness function of the GA in order to measure the fitness of solution with respect to the evaluation criteria. But, in the combined AHP-MILP approach (Tyagi and Das, 1997; Korpela and Lehmusvaara, 1999; Korpela et al., 2001a; 2001b; 2002), the AHP was used to measure the relative importance weightings of the evaluation criteria, which were then incorporated into the MILP model.

It is observed that there are rooms for improvement in both approaches. For the combined AHP-GA approach, the evaluation criteria used in the AHP are all quantitative, such as total cost, total delivery day, effectiveness of capacity utilization for warehouses, and so on. Some qualitative factors, such as reliability and flexibility were neglected. These factors are crucial in the integrated logistics system because they affect the customer satisfaction directly. For the combined AHP-MILP approach, the selection of transportation route was simply based on the customer satisfaction priorities instead of minimizing the total transportation cost or maximizing the total profit. It is, therefore, believed that the transportation routes selected may not be cost effective. To refine the above approaches, the first critical thing is to select the appropriate evaluation criteria. Both quantitative (e.g., transportation cost, delivery time, and due date) and qualitative (e.g., reliability, flexibility, and strategic importance of customers) factors should be considered. Second, besides the general constraints, such as the supply of manufacturers, demand of customers, capacities of warehouses and vehicles, numbers of warehouses and vehicles, some customer-based 
constraints (e.g., maximum waiting time of customers) should be considered. This approach can definitely generate the promising transportation routes, which not only lead to the reduction of total expenditure but also increasing of customer satisfaction.

For the product design selection, only the combined AHP-QFD approach (Wang et al., 1998; Hsiao, 2002; Kwong and Bai, 2002; 2003; Madu et al., 2002; Myint, 2003) was applied. As the case with the transportation route selection, the major difference between these six papers is due to the application of the AHP. Four papers (Wang et al., 1998; Hsiao, 2002; Madu et al., 2002; Myint, 2003) adopted the classical AHP to prioritize the customer requirements, whereas two papers (Kwong and Bai, 2002; 2003) introduced fuzzy numbers in the pairwise comparison of the AHP.

Among them, two papers need to be refined. Wang et al. (1998) represented the house of quality as a hierarchical structure, in which the customer requirements and design attributes were located in the second and third levels, respectively (the first level is the goal of problem). The author applied the AHP simply to evaluate the relative importance weightings of both customer requirements and design attributes. As mentioned earlier, the importance weightings of design attributes not only depend on the importance ratings of customer requirements but also the relationship between customer requirements and design attributes. It is, therefore, believed that the selected design attributes may not accurately reflect the customer wants. Hsiao et al. (2002) divided the customer requirements into two levels called criteria and sub-factors. The AHP was only used to measure the relative importance weightings of the criteria, but not the weightings of the sub-factors. The selection of design attributes, however, was based on the sub-factors. Similar to Wang et al. (1998), the selected design attributes may not reflect the importance of customer requirements precisely. To refine the above approaches, the AHP should be used to evaluate the relative importance weightings of customer requirements in all hierarchical levels. Based on the weightings as well as the relationship between customer requirements and design attributes, the importance weightings of design attributes are then computed.

After suggesting ways to refine the combined AHP-MILP, AHP-QFD, and AHP-GA approaches, some comments are given to the other approaches, including the combined AHP-GP, AHP-SWOT, and AHP-DEA approaches. In the combined AHP-GP approach, the AHP has two major functions. First, it can be used to evaluate the relative importance weightings of alternatives (Schniederjans and Garvin, 1997; Kwak and Lee, 1998; Radasch and Kwak, 1998; Badri, 1999; Guo and He, 1999; Kim et al., 1999; Lee and Kwak, 1999; Badri, 2001; Radcliffe and Schniederjans, 2003; Wang et al., 2004; Yurdakul, 2004; Wang et 
al., 2005; Bertolini and Bevilacqua, 2006). Second, the AHP can be applied to prioritize the levels of goal constraints in the GP model (Lee and Kwak, 1999; Zhou et al., 2000; Kwak and Lee, 2002; Kwak et al., 2005). To ensure that the decision made is more consistent, the AHP should be applied to prioritize the rankings of both alternatives and goal levels, as the case with Lee and Kwak (1999).

The combined AHP-SWOT approach is better than the stand-alone SWOT analysis because the most significant group or the intensities of strengths, weaknesses, opportunities, and threats can be known based on the quantitative AHP prioritization. Strategic planning can then be made to enhance the competitiveness. To evaluate the intensities consistently, the AHP should be used to prioritize the rankings of both SWOT group and individual SWOT factors (Kurttila et al., 2000; Kajanus et al., 2004; Shrestha et al., 2004; Masozera et al., 2006). Focusing on the weightings of the individual SWOT factors only (Shinno et al., 2006) does not pinpoint the most significant group.

One of the assumptions in the stand-alone DEA approach is that the data must be quantifiable. However, in many situations, the performance of the DMUs is influenced by some qualitative factors. To measure the performance effectively, Takamura and Tone (2003), Yang and Kuo (2003), and Ertay et al. (2006) developed the combined AHP-DEA approaches in which both qualitative and quantitative factors can be considered.

\subsection{Other observation}

The distribution of the 66 journal articles over the last decade is shown in Table 9. It is observed that there is a growth in the use of the integrated AHPs from the first five years (1997 - 2001) to the latest five years (2002 - 2006), 25 vs. 41. It is estimated that the number will keep increasing in the coming five years because of the AHP's advantages, such as ease of use, great flexibility, and wide applicability.

\section{Future work}

In this section, some possible applications of the integrated AHPs are suggested. First, the combined AHP-GP approach can be applied to the resource allocation problem in higher education. Because of gradual cuts in higher education budgeting, resource allocation should be optimized so that the performance of a university can be at least maintained or even superior to its competitors (Ho et al., 2006). In the combined AHP-GP approach, the AHP can be used to prioritize the ranking of alternative projects with respect to the goals of the universities. The GP model incorporating the constraints of AHP priority, system, and 
resource is formulated for selecting the best set of projects without exceeding the limited available resources.

The combined AHP-QFD approach can be used as an information system (e.g., e-learning platforms and e-commerce websites) development tool. In the approach, the AHP can be used to prioritize the ranking of the stakeholders' requirements and also to quantify the intensity of the relationship between the requirements and the proposed functions of the information system. Based on the consistent AHP analysis, those proposed functions with higher rankings should be incorporated into the new information system subjecting to the limited available resources (e.g., budget and human resources).

Besides the combined AHP-ANN and AHP-GA approaches, the AHP can also be integrated with the other meta-heuristics, including simulated annealing (SA) and tabu search (TS). Because the meta-heuristics have proved more efficient in solving hard optimization problems than the exact algorithms, the combined AHP-ANN, AHP-GA, AHP-SA, and AHP-TS approaches can be applied to solve the combinatorial optimization problems (e.g., the multi-depot vehicle routing problem) with multiple criteria. Unlike the traditional cost-based optimization techniques, the proposed approach considers both quantitative and qualitative factors and also aims at maximizing the benefits of deliverer and customers.

The combined AHP-DEA approach can be used to measure the efficiency of the universities. Nowadays, the funding scheme is gradually changed from direct government support to performance-related in many countries, such as United Kingdom, United States, and the Netherlands. Universities have, therefore, to manage their systems optimally and keep up their performance so that enough funding can be raised to cover necessary expenses (Ho et al., 2006). Besides resource allocation, performance measurement is one of the crucial and urgent tasks for the decision makers of universities to enhance their competitiveness. In the combined AHP-DEA approach, both quantitative factors (e.g., number of bachelor degree awarded, employment rate, number of research publications, numbers of research contracts and grants, and so on) and qualitative factors (e.g., accessibility, reputation, comprehensiveness of library, and so on) are considered.

Similar to the combined AHP-GP and AHP-DEA approaches, the combined AHP-SWOT approach can be applied to higher education. Specifically, it can be used to determine the competitiveness of the universities. In the combined AHP-SWOT approach, the AHP is used to prioritize the ranking of individual SWOT factors with respect to their equivalent SWOT group and also to prioritize the ranking of the SWOT group with respect to the goals of the universities (e.g., teaching, research, and consultancy). 


\section{Conclusions}

This paper is based on a literature review on the integrated AHPs and applications from 1997 to 2006. First, it was found that the AHP can be combined with other techniques, such as mathematical programming, QFD, meta-heuristics, SWOT, and DEA because of its simplicity and great flexibility. Comparatively, the combined AHP-GP and AHP-QFD were the two most commonly used integrated AHPs. Second, it was observed that the integrated AHPs can be applied to a wide variety of fields and problems successfully. Logistics and manufacturing are the two application areas to which the integrated AHPs were most frequently applied. Besides, some recommendations were made based on the inadequacies of some approaches. This can definitely aid the researchers and decision makers in applying the integrated AHPs effectively.

\section{Acknowledgements}

The author wishes to thank Professor Roman Slowinski and the anonymous reviewers for their critical and constructive comments. 


\section{References}

Akgunduz, A., Zetu, D., Banerjee, P., Liang, D., 2002. Evaluation of sub-component alternatives in product design processes. Robotics and Computer Integrated Manufacturing 18 (1), 69-81.

Badri, M.A., 1999. Combining the analytic hierarchy process and goal programming for global facility location-allocation problem. International Journal of Production Economics 62 (3), 237-248.

Badri, M.A., 2001. A combined AHP-GP model for quality control systems. International Journal of Production Economics 72 (1), 27-40.

Badri, M.A., Abdulla, M.H., 2004. Awards of excellence in institutions of higher education: an AHP approach. International Journal of Educational Management 18 (4), 224-242.

Bertolini, M., Bevilacqua, M., 2006. A combined goal programming-AHP approach to maintenance selection problem. Reliability Engineering and System Safety 91 (7), 839-848.

Bhattacharya, A., Sarkar, B., Mukherjee, S.K., 2005. Integrating AHP with QFD for robot selection under requirement perspective. International Journal of Production Research 43 (17), 3671-3685.

Braglia, M., Gabbrielli, R., Miconi, D., 2001. Material handling device selection in cellular manufacturing. Journal of Multi-Criteria Decision Analysis 10 (6), 303-315.

Çebi, F., Bayraktar, D., 2003. An integrated approach for supplier selection. Logistics Information Management 16 (6), 395-400.

Chan, F.T.S., Chung, S.H., 2004a. Multi-criteria genetic optimization for distribution network problems. International Journal of Advanced Manufacturing Technology 24 (7-8), 517-532.

Chan, F.T.S., Chung, S.H., 2004b. A multi-criterion genetic algorithm for order distribution in demand driven supply chain. International Journal of Computer Integrated Manufacturing 17 (4), 339-351.

Chan, F.T.S., Chung, S.H., Wadhwa, S., 2004. A heuristic methodology for order distribution in a demand driven collaborative supply chain. International Journal of Production Research 42 (1), 1-19.

Chan, F.T.S., Chung, S.H., Wadhwa, S., 2005. A hybrid genetic algorithm for production and distribution. Omega 33 (4), 345-355.

Chan, F.T.S., Chung, S.H., 2005. Multicriterion genetic optimization for due date assigned distribution network problems. Decision Support Systems 39 (4), 661-675. 
Chan, F.T.S., Chung, S.H., Choy, K.L., 2006. Optimization of order fulfillment in distribution network problems. Journal of Intelligent Manufacturing 17 (3), 307-319.

Chang, P.T., Lo, Y.T., 2001. Modelling of job-shop scheduling with multiple quantitative and qualitative objectives and a GA/TS mixture approach. International Journal of Computer Integrated Manufacturing 14 (4), 367-384.

Chuang, P.T., 2001. Combining the analytic hierarchy process and quality function deployment for a location decision from a requirement perspective. International Journal of Advanced Manufacturing Technology 18 (11), 842-849.

Crary, M., Nozick, L.K., Whitaker, L.R., 2002. Sizing the US destroyer fleet. European Journal of Operational Research 136 (3), 680-695.

Ertay, T., Ruan, D., Tuzkaya, U.R., 2006. Integrating data envelopment analysis and analytic hierarchy for the facility layout design in manufacturing systems. Information Sciences 176 (3), 237-262.

Ghodsypour, S.H., O’Brien, C., 1998. A decision support system for supplier selection using an integrated analytic hierarchy process and linear programming. International Journal of Production Economics 56-57, 199-212.

Guo, L.S., He, Y.S., 1999. Integrated multi-criterial decision model: a case study for the allocation of facilities in Chinese agriculture. Journal of Agricultural Engineering Research 73 (1), 87-94.

Hanumaiah, N., Ravi, B., Mukherjee, N.P., 2006. Rapid hard tooling process selection using QFD-AHP methodology. Journal of Manufacturing Technology Management 17 (3), 332-350.

Ho, W., Dey, P.K., Higson, H.E., 2006. Multiple criteria decision making techniques in higher education. International Journal of Educational Management 20 (5), 319-337.

Hsiao, S.W., 2002. Concurrent design method for developing a new product. International Journal of Industrial Ergonomics 29 (1), 41-55.

Kajanus, M., Kangas, J., Kurttila, M., 2004. The use of value focused thinking and the A’WOT hybrid method in tourism management. Tourism Management 25 (4), 499-506.

Kearns, G.S., 2004. A multi-objective, multi-criteria approach for evaluating IT investments: results from two case studies. Information Resources Management Journal 17 (1), $37-62$.

Kim, P.O., Lee, K.J., Lee, B.W., 1999. Selection of an optimal nuclear fuel cycle scenario by goal programming and the analytic hierarchy process. Annals of Nuclear Energy 26 (5), 449-460. 
Köksal, G., Eğitman, A., 1998. Planning and design of industrial engineering education quality. Computers \& Industrial Engineering 35 (3-4), 639-642.

Korpela, J., Lehmusvaara, A., 1999. A customer oriented approach to warehouse network evaluation and design. International Journal of Production Economics 59 (1-3), 135-146.

Korpela, J., Lehmusvaara, A., Tuominen, M., 2001a. Customer service based design of the supply chain. International Journal of Production Economics 69 (2), 193-204.

Korpela, J., Kyläheiko, K., Lehmusvaara, A., Tuominen, M., 2001b. The effect of ecological factors on distribution network evaluation. International Journal of Logistics: Research and Applications 4 (2), 257-269.

Korpela, J., Kyläheiko, K., Lehmusvaara, A., Tuominen, M., 2002. An analytic approach to production capacity allocation and supply chain design. International Journal of Production Economics 78 (2), 187-195.

Kuo, R.J., Chi, S.C., Kao, S.S., 2002. A decision support system for selecting convenience store location through integration of fuzzy AHP and artificial neural network. Computers in Industry 47 (2), 199-214.

Kurttila, M., Pesonen, M., Kangas, J., Kajanus, M., 2000. Utilizing the analytic hierarchy process (AHP) in SWOT analysis - a hybrid method and its application to a forest-certification case. Forest Policy and Economics 1 (1), 41-52.

Kwak, N.K., Lee, C.W., 1998. A multicriteria decision-making approach to university resource allocations and information infrastructure planning. European Journal of Operational Research 110 (2), 234-242.

Kwak, N.K., Lee, C.W., 2002. Business process reengineering for health-care system using multicriteria mathematical programming. European Journal of Operational Research 140 (2), 447-458.

Kwak, N.K., Lee, C.W., Kim, J.H., 2005. An MCDM model for media selection in the dual consumer/industrial market. European Journal of Operational Research 166 (1), 255-265.

Kwong, C.K., Bai, H., 2002. A fuzzy AHP approach to the determination of importance weights of customer requirements in quality function deployment. Journal of Intelligent Manufacturing 13 (5), 367-377.

Kwong, C.K., Bai, H., 2003. Determining the importance weights for the customer requirements in QFD using a fuzzy AHP with an extent analysis approach. IIE Transactions 35 (7), 619-626. 
Lam, K., Zhao, X., 1998. An application of quality function deployment to improve the quality of teaching. International Journal of Quality \& Reliability Management 15 (4), 389-413.

Lee, C.W., Kwak, N.K., 1999. Information resource planning for a health-care system using an AHP-based goal programming method. Journal of the Operational Research Society 50 (12), 1191-1198.

Lee, C.E., Hsu, S.C., 2004. Outsourcing capacity planning for an IC design house. International Journal of Advanced Manufacturing Technology 24 (3-4), 306-320.

Madu, C.N., Kuei, C., Madu, I.E., 2002. A hierarchic metric approach for integration of green issues in manufacturing: a paper recycling application. Journal of Environmental Management 64 (3), 261-272.

Malczewski, J., Moreno-Sanchez, R., Bojórquez-Tapia, L.A., Ongay-Delhumeau, E., 1997. Multicriteria group decision-making model for environmental conflict analysis in the Cape Region, Mexico. Journal of Environmental Planning and Management 40 (3), 349-374.

Malladi, S., Min, K.J., 2005. Decision support models for the selection of internet access technologies in rural communities. Telematics and Informatics 22 (3), 201-219.

Masozera, M.K., Alavalapati, J.R.R., Jacobson, S.K., Shrestha, R.K., 2006. Assessing the suitability of community-based management for the Nyungwe Forest Reserve, Rwanda. Forest Policy and Economics 8 (2), 206-216.

Myint, S., 2003. A framework of an intelligent quality function deployment (IQFD) for discrete assembly environment. Computers \& Industrial Engineering 45 (2), 269-283.

Ozdemir, M.S., Gasimov, R.N., 2004. The analytic hierarchy process and multiobjective 0-1 faculty course assignment. European Journal of Operational Research 157 (2), 398-408.

Partovi, F.Y., 1999. A quality function deployment approach to strategic capital budgeting. The Engineering Economist 44 (3), 239-260.

Partovi, F.Y., 2006. An analytic model for locating facilities strategically. Omega 34 (1), 41-55.

Partovi, F.Y., Corredoira, R.A., 2002. Quality function deployment for the good of soccer. European Journal of Operational Research 137 (3), 642-656.

Partovi, F.Y., Epperly, J.M., 1999. A quality function deployment approach to task organization in peacekeeping force design. Socio-Economic Planning Sciences 33 (2), 131-149. 
Radasch, D.K., Kwak, N.K., 1998. An integrated mathematical programming model for offset planning. Computers \& Operations Research 25 (12), 1069-1083.

Radcliffe, L.L., Schniederjans, M.J., 2003. Trust evaluation: an AHP and multi-objective programming approach. Management Decision 41 (6), 587-595.

Saaty, T.L., 1980. The Analytic Hierarchy Process. McGraw-Hill, New York.

Saaty, T.L., Vargas, L.G., Dellmann, K., 2003. The allocation of intangible resources: the analytic hierarchy process and linear programming. Socio-Economic Planning Sciences 37 (3), 169-184.

Saen, R.F., Memariani, A., Lotfi, F.H., 2005. Determining relative efficiency of slightly non-homogeneous decision making units by data envelopment analysis: a case study in IROST. Applied Mathematics and Computation 165 (2), 313-328.

Schniederjans, M.J., Garvin, T., 1997. Using the analytic hierarchy process and multi-objective programming for the selection of cost drivers in activity-based costing. European Journal of Operational Research 100 (1), 72-80.

Shinno, H., Yoshioka, H., Marpaung, S., Hachiga, S., 2006. Quantitative SWOT analysis on global competitiveness of machine tool industry. Journal of Engineering Design 17 (3), 251-258.

Shrestha, R.K., Alavalapati, J.R.R., Kalmbacher, R.S., 2004. Exploring the potential for silvopasture adoption in south-central Florida: an application of SWOT-AHP method. Agricultural Systems 81 (3), 185-199.

Stannard, B., Zahir, S., 2006. Application of analytic hierarchy process in multi-objective mixed integer programming for aircraft capacity planning. Asia-Pacific Journal of Operational Research 23 (1), 61-76.

Steuer, R.E., Na, P., 2003. Multiple criteria decision making combined with finance: a categorized bibliographic study. European Journal of Operational Research 150 (3), 496-515.

Takamura, Y., Tone, K., 2003. A comparative site evaluation study for relocating Japanese government agencies out of Tokyo. Socio-Economic Planning Sciences 37 (2), 85-102.

Tyagi, R., Das, C., 1997. A methodology for cost versus service trade-offs in wholesale location-distribution using mathematical programming and analytic hierarchy process. Journal of Business Logistics 18 (2), 77-99.

Vaidya, O.S., Kumar, S., 2006. Analytic hierarchy process: an overview of applications. European Journal of Operational Research 169 (1), 1-29. 
Wang, G., Huang, S.H., Dismukes, J.P., 2004. Product-driven supply chain selection using integrated multi-criteria decision-making methodology. International Journal of Production Economics 91 (1), 1-15.

Wang, G.., Huang, S.H., Dismukes, J.P., 2005. Manufacturing supply chain design and evaluation. International Journal of Advanced Manufacturing Technology 25 (1-2), 93-100.

Wang, H., Xie, M., Goh, T.N., 1998. A comparative study of the prioritization matrix method and the analytic hierarchy process technique in quality function deployment. Total Quality Management 9 (6), 421-430.

Yang, T., Kuo, C., 2003. A hierarchical AHP/DEA methodology for the facilities layout design problem. European Journal of Operational Research 147 (1), 128-136.

Yurdakul, M., 2004. Selection of computer-integrated manufacturing technologies using a combined analytic hierarchy process and goal programming model. Robotics and Computer-Integrated Manufacturing 20 (4), 329-340.

Zakarian, A., Kusiak, A., 1999. Forming teams: an analytic approach. IIE Transactions 31 (1), 85-97.

Zhou, Z., Cheng, S., Hua, B., 2000. Supply chain optimization of continuous process industries with sustainability considerations. Computers and Chemical Engineering 24 (2-7), 1151-1158. 


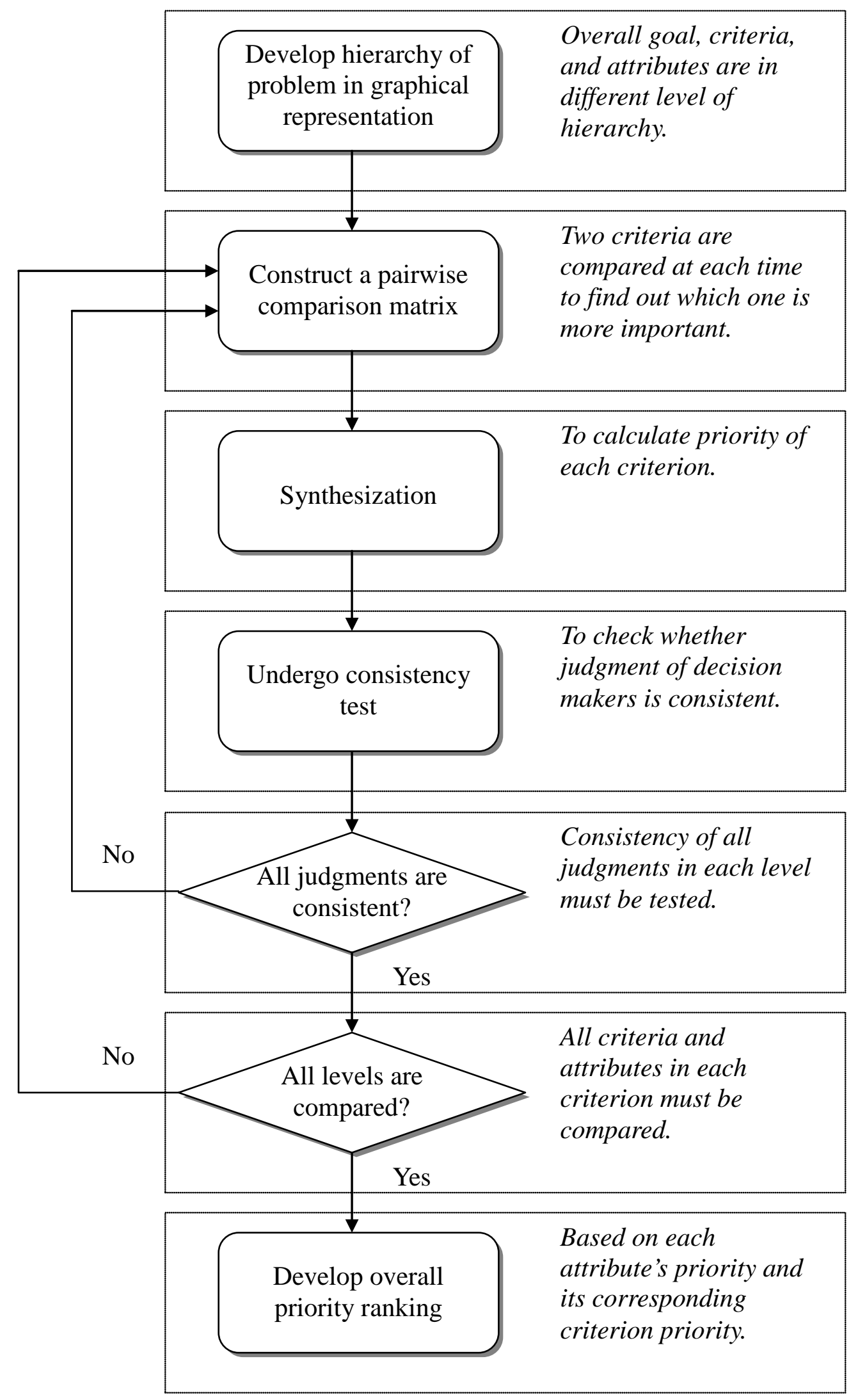

Fig. 1. The flowchart of the analytic hierarchy process (Ho et al., 2006). 
Table 1

The combined AHP-mathematical programming approaches and their applications

\begin{tabular}{llll}
\hline Approaches & Authors & Applications & Specific areas \\
\hline AHP-LP & Ghodsypour and O’Brien (1998) & Logistics & Supplier selection \\
& Saaty et al. (2003) & Business & Resource allocation \\
& Lee and Hsu (2004) & Logistics & Subcontractor selection \\
AHP-ILP & Malczewski et al. (1997) & Environment & Land use pattern selection \\
& Braglia et al. (2001) & Manufacturing & Material handling device selection \\
& Akgunduz et al. (2002) & Manufacturing & Sub-component selection \\
& Çebi and Bayraktar (2003) & Logistics & Supplier selection \\
& Kearns (2004) & Business & IT-based project selection \\
& Ozdemir and Gasimov (2004) & Higher education & Faculty course assignment \\
& Tyagi and Das (1997) & Logistics & Transportation route selection \\
& Korpela and Lehmusvaara (1999) & Logistics & Transportation route selection \\
& Korpela et al. (2001a) & Logistics & Transportation route selection \\
& Korpela et al. (2001b) & Logistics & Transportation route selection \\
& Korpela et al. (2002) & Logistics & Transportation route selection \\
Crary et al. (2002) & Military & Ship selection \\
& Malladi and Min (2005) & Government & Internet access technology selection \\
& Stannard and Zahir (2006) & Government & Airlift task selection \\
& Schniederjans and Garvin (1997) & Business & Cost driver selection \\
& Kwak and Lee (1998) & Higher education & IT-based project selection
\end{tabular}




\begin{tabular}{lll} 
Radasch and Kwak (1998) & Marketing & Offset proposal selection \\
Badri (1999) & Logistics & Facility location selection \\
Guo and He (1999) & Agriculture & Harvesting measure selection \\
Kim et al. (1999) & Military & Nuclear fuel cycle selection \\
Lee and Kwak (1999) & Health-care & IT-based project selection \\
Zhou et al. (2000) & Logistics & Scheduling plan selection \\
Badri (2001) & Service & Customer data collection method selection \\
Kwak and Lee (2002) & Health-care & IT-based project selection \\
Radcliffe and Schniederjans (2003) & Industry & Trust factor selection \\
Wang et al. (2004) & Logistics & Supplier selection \\
Yurdakul (2004) & Manufacturing & Computer-integrated manufacturing \\
Kwak et al. (2005) & technology selection \\
Wang et al. (2005) & Marketing & Advertising medium selection \\
Bertolini and Bevilacqua (2006) & Logistics & Supplier selection \\
\hline
\end{tabular}


Table 2

The combined AHP-QFD approach and its applications

\begin{tabular}{llll}
\hline Approach & Authors & Applications & Specific areas \\
\hline AHP-QFD & Köksal and Eğitman (1998) & Higher education & Education requirement selection \\
& Lam and Zhao (1998) & Higher education & Teaching method selection \\
& Wang et al. (1998) & Manufacturing & Product design selection \\
& Partovi (1999) & Manufacturing & Capital budgeting project selection \\
& Partovi and Epperly (1999) & Military & Peacekeeping force composition selection \\
Zakarian and Kusiak (1999) & Manufacturing & Multi-functional team selection \\
Chuang (2001) & Logistics & Facility location selection \\
& Hsiao (2002) & Manufacturing & Product design selection \\
& Kwong and Bai (2002) & Manufacturing & Product design selection \\
& Madu et al. (2002) & Manufacturing & Product design selection \\
& Partovi and Corredoira (2002) & Sports & Game rule selection \\
Kwong and Bai (2003) & Manufacturing & Product design selection \\
& Myint (2003) & Manufacturing & Product design selection \\
Bhattacharya et al. (2005) & Manufacturing & Robot selection \\
Partovi (2006) & Logistics & Facility location selection \\
Hanumaiah et al. (2006) & Manufacturing & Rapid tooling process selection \\
\hline
\end{tabular}


Table 3

The combined AHP-meta-heuristics approaches and their applications

\begin{tabular}{llll}
\hline Approaches & Authors & Applications & Specific areas \\
\hline AHP-ANN & Kuo et al. (2002) & Logistics & Convenience store location selection \\
AHP-GA & Chang and Lo (2001) & Manufacturing & Job shop schedule selection \\
& Chan and Chung (2004a) & Logistics & Transportation route selection \\
& Chan and Chung (2004b) & Logistics & Transportation route selection \\
& Chan et al. (2004) & Logistics & Transportation route selection \\
& Chan et al. (2005) & Logistics & Transportation route selection \\
& Chan and Chung (2005) & Logistics & Transportation route selection \\
& Chan et al. (2006) & Logistics & Transportation route selection \\
\hline
\end{tabular}

\section{Table 4}

The combined AHP-SWOT approach and its applications

\begin{tabular}{llll}
\hline Approach & Authors & Applications & Specific areas \\
\hline AHP-SWOT & Kurttila et al. (2000) & Environment & Factor evaluation in forest planning \\
& Kajanus et al. (2004) & Tourism & Factor evaluation in rural tourism planning \\
& Shrestha et al. (2004) & Agriculture & Factor evaluation in silvopasture adoption \\
& Masozera et al. (2006) & Environment & Factor evaluation in forest planning \\
& Shinno et al. (2006) & Manufacturing & Factor evaluation in competitive analysis \\
\hline
\end{tabular}


Table 5

The combined AHP-DEA approach and its applications

\begin{tabular}{llll}
\hline Approach & Authors & Applications & Specific areas \\
\hline AHP-DEA & Takamura and Tone (2003) & Government & Government agency location selection \\
& Yang and Kuo (2003) & Manufacturing & Facility layout selection \\
& Saen et al. (2005) & Government & Performance evaluation \\
& Ertay et al. (2006) & Manufacturing & Facility layout selection \\
\hline
\end{tabular}




\section{Table 6}

Summary of applications

\begin{tabular}{|c|c|c|}
\hline Applications & $\begin{array}{l}\text { No. of } \\
\text { articles }\end{array}$ & Authors \\
\hline Logistics & 21 & $\begin{array}{l}\text { Tyagi and Das (1997), Ghodsypour and O’Brien (1998), Badri } \\
\text { (1999), Korpela and Lehmusvaara (1999), Zhou et al. (2000), } \\
\text { Chuang (2001), Korpela et al. (2001a), Korpela et al. (2001b), } \\
\text { Korpela et al. (2002), Kuo et al. (2002), Çebi and Bayraktar } \\
\text { (2003), Chan and Chung (2004a), Chan and Chung (2004b), } \\
\text { Chan et al. (2004), Lee and Hsu (2004), Wang et al. (2004), } \\
\text { Chan et al. (2005), Chan and Chung (2005), Wang et al. } \\
\text { (2005), Chan et al. (2006), Partovi (2006) }\end{array}$ \\
\hline Manufacturing & 18 & $\begin{array}{l}\text { Wang et al. (1998), Partovi (1999), Zakarian and Kusiak } \\
\text { (1999), Braglia et al. (2001), Chang and Lo (2001), Akgunduz } \\
\text { et al. (2002), Hsiao (2002), Kwong and Bai (2002), Madu et } \\
\text { al. (2002), Kwong and Bai (2003), Myint (2003), Yang and } \\
\text { Kuo (2003), Yurdakul (2004), Bhattacharya et al. (2005), } \\
\text { Bertolini and Bevilacqua (2006), Ertay et al. (2006), } \\
\text { Hanumaiah et al. (2006), Shinno et al. (2006) }\end{array}$ \\
\hline Government & 4 & $\begin{array}{l}\text { Takamura and Tone (2003), Malladi and Min (2005), Saen et } \\
\text { al. (2005), Stannard and Zahir (2006) }\end{array}$ \\
\hline Higher education & 4 & $\begin{array}{l}\text { Köksal and Eğitman (1998), Kwak and Lee (1998), Lam and } \\
\text { Zhao (1998), Ozdemir and Gasimov (2004) }\end{array}$ \\
\hline Business & 3 & $\begin{array}{l}\text { Schniederjans and Garvin (1997), Saaty et al. (2003), Kearns } \\
\text { (2004) }\end{array}$ \\
\hline Environment & 3 & $\begin{array}{l}\text { Malczewski et al. (1997), Kurttila et al. (2000), Masozera et } \\
\text { al. (2006) }\end{array}$ \\
\hline Military & 3 & $\begin{array}{l}\text { Kim et al. (1999), Partovi and Epperly (1999), Crary et al. } \\
\text { (2002) }\end{array}$ \\
\hline Agriculture & 2 & Guo and He (1999), Shrestha et al. (2004) \\
\hline Health-care & 2 & Lee and Kwak (1999), Kwak and Lee (2002) \\
\hline Marketing & 2 & Radasch and Kwak (1998), Kwak et al. (2005) \\
\hline Industry & 1 & Radcliffe and Schniederjans (2003) \\
\hline Service & 1 & Badri (2001) \\
\hline Sports & 1 & Partovi and Corredoira (2002) \\
\hline Tourism & 1 & Kajanus et al. (2004) \\
\hline Total & 66 & \\
\hline
\end{tabular}


Table 7

Summary of approaches used in logistics

\begin{tabular}{|c|c|c|c|c|}
\hline Application & Specific areas & Approaches & $\begin{array}{l}\text { No. of } \\
\text { articles }\end{array}$ & Authors \\
\hline \multirow[t]{10}{*}{ Logistics } & Transportation route selection & AHP-GA & 6 & $\begin{array}{l}\text { Chan and Chung (2004a), Chan and Chung (2004b), } \\
\text { Chan et al. (2004), Chan et al. (2005), Chan and Chung } \\
\text { (2005), Chan et al. (2006) }\end{array}$ \\
\hline & & AHP-MILP & 5 & $\begin{array}{l}\text { Tyagi and Das (1997), Korpela and Lehmusvaara } \\
\text { (1999), Korpela et al. (2001a), Korpela et al. (2001b), } \\
\text { Korpela et al. (2002) }\end{array}$ \\
\hline & Supplier/Subcontractor selection & AHP-LP & 2 & Ghodsypour and O’Brien (1998), Lee and Hsu (2004) \\
\hline & & AHP-GP & 2 & Wang et al. (2004), Wang et al. (2005) \\
\hline & & AHP-ILP & 1 & Çebi and Bayraktar (2003) \\
\hline & $\begin{array}{l}\text { Facility/Convenience store location } \\
\text { selection }\end{array}$ & AHP-QFD & 2 & Chuang (2001), Partovi (2006) \\
\hline & & AHP-GP & 1 & Badri (1999) \\
\hline & & AHP-ANN & 1 & Kuo et al. (2002) \\
\hline & Scheduling plan selection & AHP-GP & 1 & Zhou et al. (2000) \\
\hline & & Total & 21 & \\
\hline
\end{tabular}




\section{Table 8}

Summary of approaches used in manufacturing

\begin{tabular}{|c|c|c|c|c|}
\hline Application & Specific areas & Approaches & $\begin{array}{l}\text { No. of } \\
\text { articles }\end{array}$ & Authors \\
\hline \multirow[t]{13}{*}{ Manufacturing } & Product design selection & AHP-QFD & 6 & $\begin{array}{l}\text { Wang et al. (1998), Hsiao (2002), Kwong and Bai } \\
\text { (2002), Madu et al. (2002), Kwong and Bai (2003) } \\
\text { Myint (2003) }\end{array}$ \\
\hline & Facility layout selection & AHP-DEA & 2 & Yang and Kuo (2003), Ertay et al. (2006) \\
\hline & Material handling device selection & AHP-ILP & 1 & Braglia et al. (2001) \\
\hline & Sub-component selection & AHP-ILP & 1 & Akgunduz et al. (2002) \\
\hline & $\begin{array}{l}\text { Computer-integrated manufacturing } \\
\text { technology selection }\end{array}$ & AHP-GP & 1 & Yurdakul (2004) \\
\hline & Maintenance strategy selection & AHP-GP & 1 & Bertolini and Bevilacqua (2006) \\
\hline & Capital budgeting project selection & AHP-QFD & 1 & Partovi (1999) \\
\hline & Multi-functional team selection & AHP-QFD & 1 & Zakarian and Kusiak (1999) \\
\hline & Robot selection & AHP-QFD & 1 & Bhattacharya et al. (2005) \\
\hline & Rapid tooling process selection & AHP-QFD & 1 & Hanumaiah et al. (2006) \\
\hline & Job shop schedule selection & AHP-GA & 1 & Chang and Lo (2001) \\
\hline & $\begin{array}{l}\text { Factor evaluation in competitive } \\
\text { analysis }\end{array}$ & AHP-SWOT & 1 & Shinno et al. (2006) \\
\hline & & Total & 18 & \\
\hline
\end{tabular}


Table 9

Distribution of number of journal articles over the last 10 years

\begin{tabular}{ll}
\hline Years & No. of articles \\
\hline 1997 & 3 \\
1998 & 6 \\
1999 & 8 \\
2000 & 2 \\
2001 & 6 \\
2002 & 9 \\
2003 & 7 \\
2004 & 10 \\
2005 & 7 \\
2006 & 8 \\
& Total \\
\hline
\end{tabular}




\section{University Library}

\section{- M M N E R VA A gateway to Melbourne's research publications}

Minerva Access is the Institutional Repository of The University of Melbourne

Author/s:

Ho, W

Title:

Integrated analytic hierarchy process and its applications - A literature review

Date:

2008-04-01

Citation:

Ho, W. (2008). Integrated analytic hierarchy process and its applications - A literature review. EUROPEAN JOURNAL OF OPERATIONAL RESEARCH, 186 (1), pp.211-228. https:// doi.org/10.1016/j.ejor.2007.01.004.

Persistent Link:

http://hdl.handle.net/11343/118683 